\title{
Inhalt des drei und zwanzigsten Bandes.
}

\author{
E r s t e s $H$ e f $t$.
}

1. Die Girardsche Schiffschleuse mit Schwimmer. . . . . . . . . Seite 1

2. Ein auf Erfahrung gegründeter Vorschlag, auch Băche für die Fortbringung von Lasten fahrbar zu machen. Von Hern Heinrich Freiherrn v.Pechmann, Königl. Baierischem Gebeimen-Ober-Baurathe. . . . . . . . . . - 39

3. Einige Nachrichten von den Entwürfen zu einem Schiffahrts-Canal durch die Land-Enge von Panama. (Fortsetzung des Aufsatzes No. 12. im 3ten und No. 18. im 4ten Hefte 22ten Bandes.) . . . . . . . . . . . . . - 5

4. Historisch - hydrographische Nachrichten von den Häfen und andern Schifffahrts-Anstalten Ostfrieslands bei der Stadt Emden und in den Emsmündungen, nebst practischen Vorschlägen zur Verbesserung des Fahrwassers, zur völligen Sicherung der Stadt und Umgegend gegen Zerstörung durch hohe Sturmfluthen, und zur Vermehrung der innern EntwässerungsAnlagen des Binnenlandes zum Besten der Landwirthschaft. Von D. Reirlhold, Königl. Hannöverschem Wasserbau-Inspector. (Fortsetzung der Abhandlung No. 1. im ersten, No. 8. im zweiten, No. 16. im vierten Hefte ein und zwanzigsten und No. 14. im dritten Hefte zwei und zwanzigsten Bandes.)

$$
\mathrm{Z} \text { w } \theta \text { i } \mathrm{t} \text { e s } H \text { ef } t \text {. }
$$

5. Über die Baumaterialien des alten und des neuen Griechenlands, und über die geognostischen Verhăltnisse dieses Landes. Von Herrn F. Stauffert, ehemaligem Stadt-Architekten von Athen in den Jahren von 1835 bis 15ten September 1843. (Die Fortsetzung folgt.) . . . . . . .

6. Historisch-hydrographische Nachrichten von den Häfen und andern Schiffahrts-Anstalten Ostfrieslands bei der Stadt Emden und in den Emsmündungen, nebst practischen Vorschlägen zur Verbesserung des Fahrwassers, zur völligen Sicherung der Stadt und Umgegend gegen Zerstörung durch hohe Sturmfluthen und zur Vermehrung der inuern Entwăsserungs - Anlagen des Binnenlandes zum Besten der Landwirthschaft. Von D. Reiuhold, Königl. Hannöverschem Wasserbau-Inspector. (Schlufs der Abhandlung No. 1. im ersten, No. 8. im zweiten, No. 16. im vierten Hefte 21 ten, No. 14. im dritten Hefte 22ten und No. 4. im ersten Hefte Die Girardsche Schiffschleuse mit Schwimmer. (Fortsetzung der Abhandlung No. 1. im vorigen Hefte.) . . . . . . . . . . . . . . . - 172 
D r i t t e s H e f t.

8. Des Grafen v. Pambour "Theorie der Dampfmaschinen." Nach der zweiten Auflage dieses Werkes von 1844; möglichst kurz; und mit einigen Anmerkungen des Herausgebers dieses Journals. . . . . . . . Seite 201

9. Die Girardsche Schiffschleuse mit Schwimmer. (Fortsetzung der Abhaudlung No. 1. im 1ten und No. 7. im 2ten Heft dieses Bandes.) . . - 252

10. Uber die Baumaterialien des alten und des neuen Griechenlands, und über die geognostischen Verhältnisse dieses Landes. Von Herrn F. Stauffert, ehemaligem Stadt-Architekten von Athen in den Jahren von 1835 bis 15ten September 1843. (Fortsetzung der Abhandlung No. 5. im vorigen Heft.)

\section{Vie r t e s $H$ e f $t$.}

11. Über die Baumaterialien des alten und des neuen Griechenlands, und über die geognostischen Verhältnisse dieses Landes. Von Herrn F. Stauffert, ehemaligem Stadt-Architecten in Athen in den Jahren von 1835 bis 15̆ten September 1843. (Schlufs der Abhandlung No. 5. im zweiten und No. 10. im dritten Heft dieses Bandes.) . . . . . . . . . . . . - 298

12. Des Grafen v. Pambour "Theorie der Damfmaschinen." Nach der zweiten Auflage dieses Werkes von 1844; möglichst kurz; und mit einigen Anmerkungen des Herausgebers dieses Journals. (Fortsetzung der Abhandlung No. 8. im dritten Heft dieses Bandes.) . . . . . . . . - 320

13. Vom Portland-Cement. Dem Journale mitgetheilt von Herrn Emil Mïller in Hamburg, bei welchem der Cement zu haben ist. . . . . . . . - 368

14. Die Girardsche Schiffschleuse mit Schwimmer. (Fortsetzung der Abhandlung No. 1. im 1ten, No. 7. im 2ten und No. 9. im 3ten Heft dieses Bandes.) - 373 


\section{J o u r n a l}

f ü r

\section{d i e B a u k u n s t.}

In $z$ w a $n g$ l o s e $n$ H e f t e n.

Herausgegeben

vo

\section{Dr. A. L. C r e $l l$ e,}

Koniglich - Preufsischem Geheimen-Ober-Baurathe, Mitgliede der Kbniglichen Akademie der Wissenschaten zu Berlin, Correspondenten der Kaiserlichen Akademie der Wissenschanen zu St. Pelersburg und der Königlichen Akademieen der Wissenschaften zu Neapel und Brüssel, auswärtigem Mitgllede der Kóniglichen Akademie der Wissenschaten zu Stockholm, Ehrenmitgliede der Bamburger Gesellschaft zur Verbreitung der mathematischen Wissenschaften.

\section{Drei und zwanzigster Band.}

Erstes Heft.

Mit zwei Figurentafeln.

B e r I i n.

$B \in i$ G. $R$ e $i$ m e $r$.

1846. 
